\title{
Iatrogenic aortic dissection in an infant with persistent fifth aortic arch and congenital heart defects
}

\author{
Noritaka Okada, MD, PhD, Hiroomi Murayama, MD, and Hiroki Hasegawa, MD, PhD, Ōbu, Japan
}

\author{
From the Department of Cardiovascular Surgery, Aichi Children's Health and Medical Center, Ōbu, Aichi, Japan. \\ Disclosures: Authors have nothing to disclose with regard to commercial support. \\ Received for publication Aug 13, 2015; revisions received Oct 1, 2015; accepted for publication Oct 7, 2015; \\ available ahead of print Nov 11, 2015 \\ Address for reprints: Noritaka Okada, MD, PhD, 7-426 Morioka-cho, Ōbu, Aichi, Japan 474-8710 (E-mail: \\ cvsoka@gmail.com). \\ J Thorac Cardiovasc Surg 2016;151:e55-7 \\ $0022-5223 / \$ 36.00$ \\ Copyright (C) 2016 by The American Association for Thoracic Surgery \\ http://dx.doi.org/10.1016/j.jtcvs.2015.10.033
}

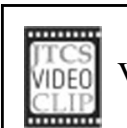

Video clip is available online.

Aortic dissection occurred during cardiac surgery in an infant with a fifth aortic arch and congenital heart defects on the Fontan track. The pathologic specimen revealed the mechanism of the dissection.

\section{CLINICAL SUMMARY}

A 1-month-old female infant with an unbalanced atrioventricular septal defect, pulmonary stenosis, patent ductus arteriosus, and a persistent fifth aortic arch underwent a right-side modified Blalock-Taussig shunt operation from the brachiocephalic artery to establish a sufficient pulmonary flow under cardiopulmonary bypass. An arterial cannula was placed at the end of the ascending aorta with a 2.4-mm angled-tip arterial cannula (JMS Co, Ltd, Hiroshima, Japan; Figure 1), which is often difficult to maintain in a fixed position toward the aorta. The perfusion line pressure was intermittently elevated above $500 \mathrm{~mm} \mathrm{Hg}$ every time that the arterial cannula was repositioned. During the procedure, the line pressure gradually increased to around $400 \mathrm{~mm} \mathrm{Hg}$. The arterial blood pressure at the lower limb eventually dropped. A subsequent direct epiaortic ultrasonographic image confirmed the aortic dissection. Because the ascending aorta was intact, the patient was immediately weaned from the cardiopulmonary bypass, and decannulation was performed to release the pressure in the pseudolumen and increase the cardiac output into the true lumen, after which the arterial blood pressure of the lower limb successfully recovered and no signs of malperfusion were observed. As a result, we did not immediately perform entry resection and evaluated the aortic state by computed tomography, which demonstrated the presence of aortic dissection, ranging from the end of the ascending aorta to just proximal to the celiac artery. The patient was treated

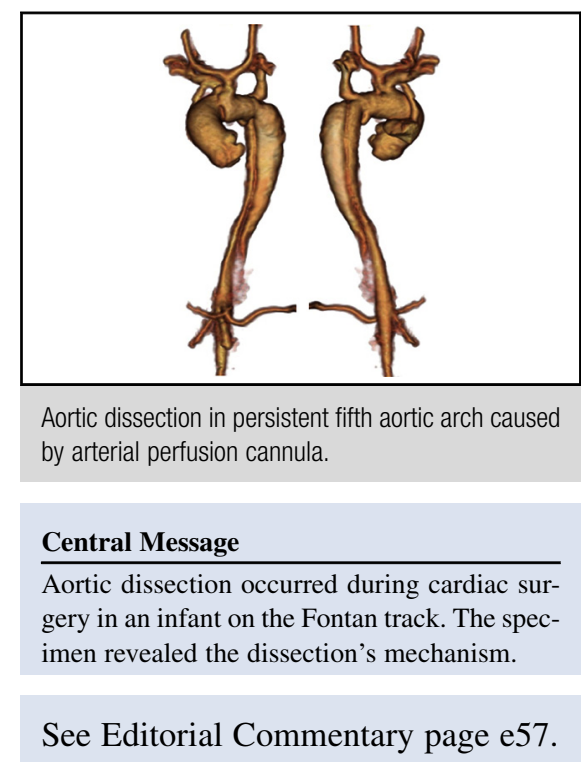

medically, which is the standard of care for uncomplicated acute type B aortic dissection; however, the false lumen gradually became dilated (Figure 2) and increased in size from $5 \mathrm{~mm}$ to $10 \mathrm{~mm}$ during the next 45 days. An angiogram showed a dominant flow in the true lumen and a slow flow and pooling of the contrast medium in the false lumen, indicating that the absence of a major reentry site and the distal perfusion did not depend on the flow from the pseudolumen (Video 1). We therefore considered that entry closure could be performed safely without a risk of lower body ischemia. At 3 months of age, the patient underwent the Glenn procedure concomitantly with entry closure under deep hypothermic circulatory arrest at a rectal temperature of $18^{\circ} \mathrm{C}$ by ascending aortic cannulation and bicaval venous drainage. The intimal defect was identified, and the aortic wall of the entry was resected. The pseudolumen was closed by fixing the intimal flap and adventitia with horizontal mattress sutures reinforced on both sides with autologous pericardium. A specimen of the resected aortic wall of the entry of the dissection demonstrated the mechanism of the aortic dissection, which was caused by perfusion pressure tearing the aortic media when the tip of the cannula became dislocated intramurally in the aortic wall (Figure 3). The original intimal hole through which the cannula was inserted could not be closed by purse-string sutures, which maintained the blood flow into the pseudolumen after decannulation. The patient did not show any postoperative neurologic deficit. Although there was a tiny residual flow in the false lumen detected by an 


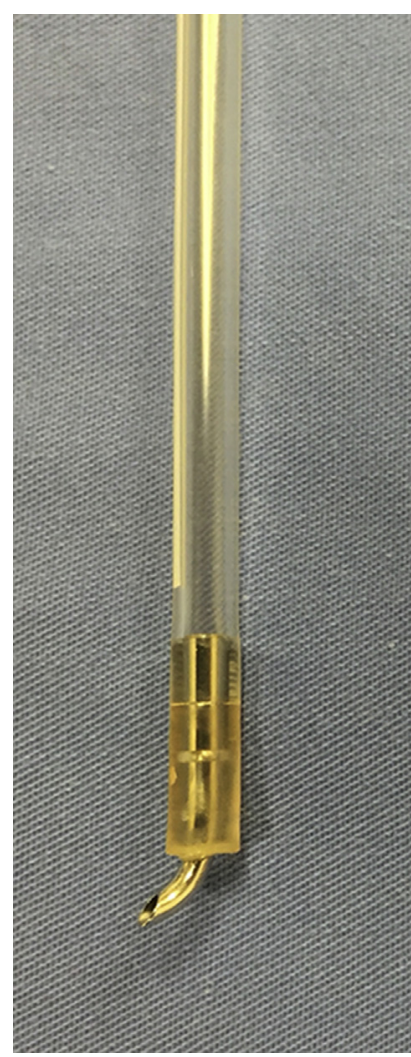

FIGURE 1. A 2.4-mm angled-tip arterial cannula used in the operation features a sharp, tapered tip.

ultrasonographic examination, computed tomographic scan at 5 months of age showed the false lumen to have decreased in diameter. The patient currently is 6 months of age and is doing well and waiting to undergo the Fontan procedure.

\section{DISCUSSION}

Aortic dissection in infants, especially in those of 1 month of age, is an extremely rare phenomenon. We report a case of iatrogenic aortic dissection caused by an arterial perfusion cannula, which is also a remarkably uncommon comorbidity in the pediatric population. ${ }^{1,2}$ Because it was a type $\mathrm{B}$ dissection and the malperfusion of the lower body disappeared after decannulation, we did not perform an aortic corrective procedure immediately, with the expectation that early thrombosis could be obtained in the false lumen. Although the dilatation of the false lumen was observed postoperatively, we fortunately had the chance to perform entry closure concomitantly with a second-stage operation on the Fontan track. We present here for the first time in the literature a specimen of the resected aortic wall of the entry site of the dissection, which revealed the mechanism of aortic dissection, along with computed tomographic images of the aortic dissection. It is often difficult to maintain this type of angled arterial
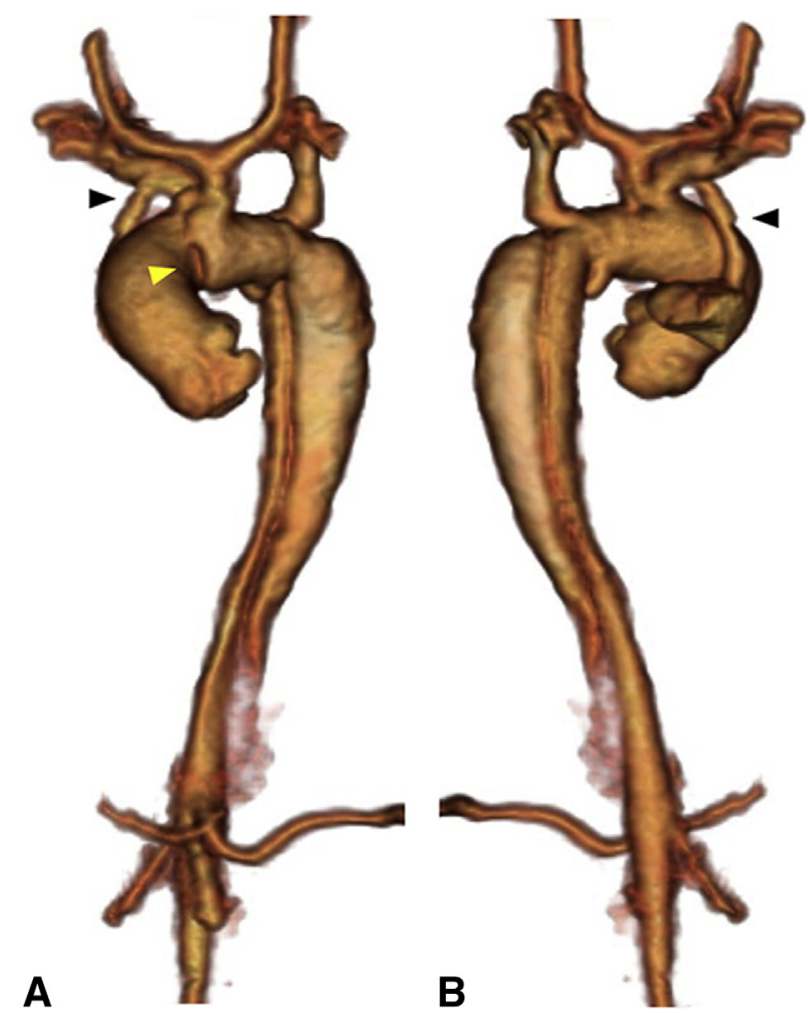

FIGURE 2. These 3-dimensional computed tomographic anterior (A) and posterior (B) views were obtained 45 days after modified Blalock-Taussig shunt operation. The entry was located in the anterior aspect of the end of the ascending aorta (yellow arrowhead), and the dissection extended just above the celiac artery. Bilateral common carotid arteries and the right subclavian artery arose from the common trunk, and the left subclavian artery separately branched from the aortic arch, which was anatomically located lower because it was diagnosed as a persistent fifth aortic arch. The black arrowhead indicates the modified Blalock-Taussig shunt.

cannula in a fixed position that allows the tip to be maneuvered toward the intended direction. This difficulty and its sharp tapered tip enhance the importance of alerting all surgeons to the possibility of this devastating complication.

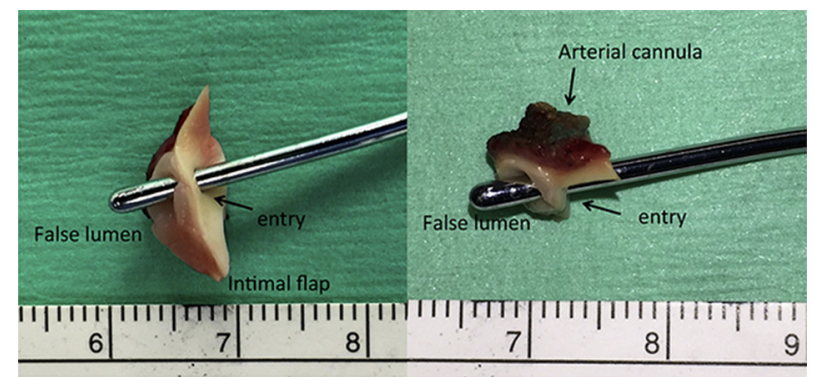

FIGURE 3. A specimen of the resected aortic wall of the entry. The arterial cannula, which inserted through the purse-string sutures, dislocated shallowly inside the aortic wall, and the perfusion pressure dissected the aortic wall distally. After decannulation, an intimal defect persisted, and it served as an entry site to the false lumen postoperatively. 
Prosthetic graft replacement is extremely difficult in this age group; the close follow-up of the state of chronic aortic dissection is therefore necessary until the complete disappearance of the false lumen has been confirmed.

\section{References}

1. Nagy Z, Heinemann MK, Schmid E, Ziemer G. Successful repair of intraoperative type-A dissection in an infant. Eur J Cardiothorac Surg. 2002;22:636-7.

2. Walther T, Kiefer H, Dähnert I, Kostelka M. Successful treatment for intraoperatively evolving acute aortic dissection in a neonate. Ann Thorac Surg. 2003;76:1286-7.

\title{
EDITORIAL COMMENTARY
}

\section{Acting on a rare event}

\author{
Osami Honjo, MD, PhD
}

From the Division of Cardiovascular Surgery, The Hospital for Sick Children, Toronto, Ontario, Canada. Disclosures: Author has nothing to disclose with regard to commercial support.

Received for publication Nov 9, 2015; accepted for publication Nov 10, 2015; available ahead of print Dec 10, 2015.

Address for reprints: Osami Honjo, MD, PhD, Division of Cardiovascular Surgery, The Hospital for Sick Children, 555 University Ave, Toronto, Ontario M5G 1X8, Canada (E-mail: osami.honjo@ sickkids.ca). J Thorac Cardiovasc Surg 2016;151:e57-8 $0022-5223 / \$ 36.00$

Copyright (C) 2016 by The American Association for Thoracic Surgery http://dx.doi.org/10.1016/j.jtcvs.2015.11.012

Arterial cannulation in neonates and small infants is a technical challenge because of the size mismatch between the small aorta and a large arterial cannula. We often experience fluctuation of the arterial inflow pressure due to subtle positional changes of the cannula. The cannula-related iatrogenic aortic dissection is much more common in the adult population, presumably as a result of atherosclerotic changes of the aortic wall. ${ }^{1}$ Despite considerable risk of potential aortic intimal injury in the pediatric population, the incidence of aortic dissection in the pediatric population is extremely rare.

Okada and colleagues ${ }^{2}$ reported a rare but important iatrogenic complication related to arterial cannulation in a small infant with unbalanced atrioventricular septal defect who underwent placement of a systemic-to-pulmonary shunt under cardiopulmonary bypass. Intermittent, but extremely high, arterial line pressures, followed by a drop in the lower arterial pressure, were noted. Type B aortic dissection was diagnosed initially using epi-aortic ultrasound. The situation was promptly managed by termination of cardiopulmonary bypass and decannulation, followed by definitive diagnosis with a CT scan. The intimal tear was resected at the time of stage II palliation.

Acting on an extremely rare complication in a timely manner is often difficult in the cardiac operation room. The authors managed to diagnose and manage acute iatrogenic aortic dissection promptly and successfully, to prevent further extension of dissection or organ malperfusion. This

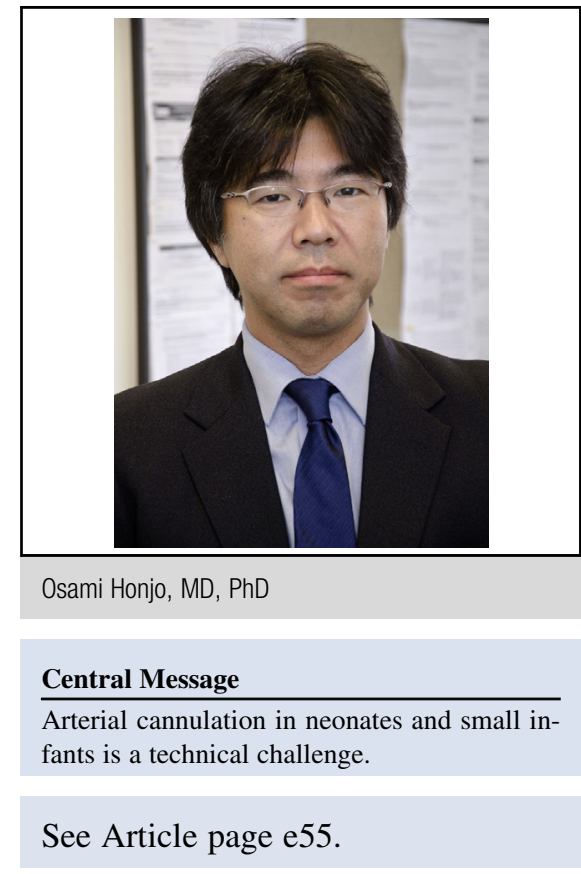

case was very fortunate in the sense that dissection did not extend to the proximal aortic root or abdominal aorta. Salvaging organ ischemia related to acute dissection that involved major abdominal aortic branches in neonates or small infants would be almost impossible.

Blood pressure management during the observation period in this case is unclear from the report, but it would be very difficult to set and manage a target blood pressure in an infant who has an obvious entry point but no effective re-entry point to decompress the false lumen. In this particular case, the patient had an in-parallel circulation with a systemic-to-pulmomary shunt, in which change in systemic vascular resistance, either by blood pressure management or significant extension of aortic dissection, can be critical. 